\title{
POTENCIALIDADES DO USO DE TIRINHAS NA PEDAGOGIA DE PROJETOS: EDUCAÇÃO GEOGRÁFICA EM QUESTÃO
}

\author{
Fabrício Oliveira da Silva ${ }^{1}$ \\ Rodrigo Pereira Ribeiro²
}

\section{RESUMO}

O presente artigo faz reflexões em torno da potencialidade da pedagogia de projetos para o ensino da educação geográfica. Visa compreender como o gênero textual tirinhas pode ser uma interessante estratégia para o desenvolvimento da metodologia ancorada em pedagogia projetos com vistas a pensar educação geográfica. Para isso, foi realizado um estudo bibliográfico sobre pedagogia de projetos, educação geográfica e tirinhas. Na primeira parte discutimos o que é pedagogia de projetos e diferenciamos educação geográfica de ensino de geografia. Na segunda parte, delimitamos o semiárido como um tema a ser trabalhado na pedagogia de projetos. Na terceira, evidenciamos como a pedagogia de projetos pode potencializar a articulação entre diferentes conhecimentos, como o geográfico e o textual, em que as tirinhas se insurgem como interessante estratégia de ensino de questões geográficas a partir das especificidades do gênero textual. $E$ na última, mas não menos importante, discutimos sobre o gênero textual tirinhas e suas potencialidades para se fazer uma educação pautada na produção de virtudes intelectuais. Como resultado

\footnotetext{
${ }^{1}$ Pós-Doutor e Doutor em Educação pelo Programa de Pós-Graduação em Educação e Contemporaneidade - PPGEduC da Universidade do Estado da Bahia - UNEB. Pósdoutorando em Educação. Professor da Universidade Estadual de Feira de Santana UEFS. Professor Permanente do Programa de Pós-Graduação em Educação - PPGE da UEFS. Coordenador do Núlceo de Estudos e Pesquisas sobre Pedagogia Universitária NEPPU da UEFS. Pesquisador do Grupo de pesquisa Docência, Narrativas e Diversidade na Educação Básica - DIVERSO, grupo ligado aoPPGEduC - UNEB. ORCID: http://orcid.org/0000-0002-7962-7222. E-mail: fosilva@uefs.br

${ }^{2}$ Especialista em Ensino de Geografia. Graduação em Licenciatura em Geografia pela Universidade Estadual de Feira de Santana (2019). Foi bolsista do PIBID (2017 - 2018) e da Residência Pedagógica (2018 - 2019).ORCID: https://orcid.org/0000-0003-4449-683X Email: ribeirorodrigopereira@gmail.com
} 
evidenciamos que as tirinhas geram a condição de produção de interdisciplinaridade, fato que torna a educação geográfica mais interessante, dinâmica e possibilitadora da criatividade e inventividade dos estudantes.

Palavras-Chave: Pedagogia de Projetos. Educação Geográfica. Tirinhas.

\section{POTENTIALS OF THE USE OF STRIPES IN PROJECT PEDAGOGY: GEOGRAPHICAL EDUCATION IN QUESTION}

\section{ABSTRACT}

This article reflects on the potential of project pedagogy for teaching geographical education. Aims to understand how the textual genre can be an interesting strategy for the development of methodology anchored in pedagogy projects with a view to thinking geographical education. For this, a bibliographical study was carried out on project pedagogy, geographic education and comic strips. In the first part we discuss what is project pedagogy and differentiate geographical education from geography teaching. In the second part, we delimit the semiarid as a theme to be worked on in project pedagogy. In the third, we highlight how project pedagogy can potentialize the articulation between different knowledge, such as geographical and textual, in which the comic strips appear as an interesting strategy for teaching geographical issues based on the specificities of the textual genre. And last but not least, we discuss about the textual genre comic strips and their potential to make an education based on the production of intellectual virtues. As a result, we show that the comic strips generate the condition of production of interdisciplinarity, a fact that makes geographic education more interesting, dynamic and enabling the creativity and inventiveness of students.

Keywords: Project Pedagogy. Geographical Education. Comic Strips. 


\section{POTENCIALIDADES DEL USO DE HISTORIETAS EN LA PEDAGOGÍA DE PROYECTOS: EDUCACIÓN GEOGRÁFICA EN CUESTIÓN}

\section{RESUMEN}

Este artículo reflexiona sobre el potencial de la pedagogía del proyecto para enseñar educación geográfica. Su objetivo es comprender cómo las historietas del género textual pueden ser una estrategia interesante para el desarrollo de la metodología anclada en proyectos de pedagogía con miras a pensar en la educación geográfica. Para ello, se realizó un estudio bibliográfico sobre pedagogía del proyecto, educación geográfica y historietas. En la primera parte, discutimos qué es la pedagogía del proyecto y diferenciamos la educación geográfica de la enseñanza de geografía. En la segunda parte, definimos el semiárido como un tema para trabajar en la pedagogía de los proyectos. En el tercero, mostramos cómo la pedagogía de los proyectos puede mejorar la articulación entre diferentes conocimientos, como el geográfico y el textual, en el que las historietas emergen como una estrategia interesante para enseñar temas geográficos basados en las especificidades del género textual. $Y$ en el último, pero no menos importante, discutimos el género textual de las historietas y su potencial para una educación basada en la producción de virtudes intelectuales. Como resultado, mostramos que las tiras generan la condición de producción de interdisciplinariedad, un hecho que hace que la educación geográfica sea más interesante, dinámica y permite la creatividad e inventiva de los estudiantes.

Palabras clave: Pedagogía del Proyecto. Educación Geográfica Tiras.

\section{INTRODUÇÃO}

Pensar o ensino na contemporaneidade, implica entender que o estudante se torna protagonista do processo, sendo ele o sujeito das ações que desenvolve para aprender. Neste sentido, a escola tem avançado na direção de buscar desenvolver ações que possibilitem o 
estudante a significar e a ressignificar o que aprende no cotidiano de sua formação. No campo da geografia, mais especificamente na educação geográfica, que tem por prerrogativa possibilitar que o estudante desenvolva virtudes intelectuais por meio das quais ele tome consciência e analise o espaço geográfico com maior criteriosidade, tem sido recorrente as tentativas de pensar a geografia escolar pelo viés da dinamicidade, em que o estudante gera autonomias para as reflexões que produz. Nessa seara, a pedagogia de projetos congrega elementos interessantes para a promoção da autonomia estudantil, uma vez que nessa metodologia, os estudantes devem exercer a aprendizagem ancorada na curiosidade e na decisão daquilo que ele busca entender, e consequentemente, aprender.

$\mathrm{Na}$ formação de professores a produção de estratégias de ensino e de aprendizagem são tecidas reflexivamente em diversos momentos do processo de formação, tendo em vista a necessidade dos professores se apropriarem e desenvolverem modos próprios de desenvolver a docência para a qual estão em franca formação. Assim sendo, os estágios supervisionados, assim como outros programas de formação, tais como o Programa Institucional de Bolsas de Iniciação à Docência - PIBID e o Residência Pedagógica, tem sido espaços em que os estudantes de licenciatura buscam experienciar diferentes metodologias para o desenvolvimento do ensino. É comum, portanto, que os licenciandos motivem-se a produzir leituras e reflexões em torno de diversas metodologias, na perspectiva de produzirem modos próprios de aprender a ser professor.

Assim sendo, a ideia de pesquisar sobre pedagogia de projetos foi gerada a partir do estágio supervisionado (na modalidade de regência) durante o qual questionamos aspectos da relação professor $x$ aluno x conhecimento na Educação Básica. Nossa busca foi orientada por uma reflexão em torno das possibilidades de se promover uma educação mais centrada na aprendizagem dos estudantes que no ensino dos professores. Foi a partir desta compreensão que pesquisamos e encontramos, na construção de projetos mediados pela linguagem das tirinhas, uma alternativa condizente com a nossa perspectiva de ensino e aprendizagem no campo da geografia. 
Discutir sobre educação geográfica, ao nosso ver, se fez necessário, haja vista que trabalhar com pedagogia de projetos exige que o professor priorize mais a aprendizagem do que o ensino, entendo que a educação geográfica tem importantes contribuições para isso.

Uma das etapas de um projeto remete-se a elaboração de um produto, para isso decidimos escolher o gênero textual tirinha. A razão dessa escolha se justificou, entre outras razões, pelo fato de que as tirinhas mesclam diferentes gêneros textuais, imagem e texto, possibilitando produções de sentido de forma reduzida e impactante, o que corrobora com a possibilidade do estudante tornar-se criativo, e inventivo em torno das compreensões e interpretações que faz do espaço geográfico. Neste trabalho defendemos a importância das tirinhas como uma linguagem passível de sistematizar o que foi produzido durante o projeto, através do recurso textual e gráfico.

\section{O QUE É A PEDAGOGIA DE PROJETOS? POR QUE UTILIZÁ-LA?}

Moura (2010) discorre sobre a origem da palavra projeto, afirmando que esta deriva do latim projectus, que significa algo lançado para frente. Logo se concebe a ideia de projeto como uma ideia que se assenta na lógica de se sair de onde se encontra em busca de novas soluções. A Pedagogia de projetos está inspirada na concepção de "método de projetos", que no campo educacional emergiu com uma perspectiva pedagógica com vistas a contrapor-se aos princípios e métodos da escola tradicional, que reforçava o sistema de produção em série (taylorista/ fordista), cuja filosofia de trabalho concentrava o capital, o poder e o saber nas mãos de poucos.

Na contramão de se manter uma educação transmissiva na década de 2000, a maioria dos países, dentre os quais se incluída o Brasil se deu início ao reordenamento dos Currículos. Tal situação provocou tensionamentos e polêmicas, em torno das perspectivas pedagógicas e da necessidade de criar autonomias nos estudantes. Nessa seara, o debate de reforma curricular tornou-se alvo de intensas polêmicas, envolvendo ministérios da educação, universidades, associações e órgãos de classe de professores. 
Especificamente no contexto educacional brasileiro, é aprovada a nova Lei de Diretrizes e Bases da Educação Nacional - LDB, os Parâmetros Curriculares Nacionais são redefinidos e o Plano Nacional de Educação (2001) passa a vigorar com prazo de dez anos para sua implementação.

Foi nessa dimensão histórica do cenário educacional brasileiro que ganha centralidade a perspectiva de trabalho em torno da Pedagogia de Projetos. Nessa lógica, a construção do saber emerge das perspectivas de se trabalhar um tema sob o prisma de olhares multifacetados de professores e estudantes, em que a aprendizagem se configura como algo motivado pela curiosidade e inventividade dos professores e dos estudantes. O cotidiano escolar emerge como palco das reflexões pedagógicas que se produzem em torno dos projetos desenvolvidos, gerando uma espécie de aprendizagem experiencial, entendida como aquela que acontece com os sujeitos envolvidos, por eles se permitirem viver situações educativas no espaço educativo para a qual atribuem sentidos (SILVA; RIOS, 2018)

A pedagogia de projetos é uma das múltiplas alternativas que o professor pode utilizar em sala de aula. Inspirada na concepção construtivista, a pedagogia de projetos procura desenvolver um conjunto de estratégias de trabalho no qual os estudantes são ativos no processo - sujeitos de sua aprendizagem - e não apenas receptores. Portanto, é uma perspectiva em oposição às estratégias mais comuns centradas em aulas expositivas ancoradas em um modelo transmissivo de conhecimento, portanto, centrada, fundamentalmente, no ensino do professor.

Acreditamos que a Pedagogia de Projetos deva ser vista não como um modelo rígido, mas como uma alternativa que agregue novas possibilidades de apropriação e produção de conhecimento que favoreçam o desenvolvimento intelectual do alunado. Segundo Ludke (2003), a pedagogia de projetos produz várias rupturas paradigmáticas do trabalho educativo, dentre as quais destaca-se a articulação entre trabalho individual e coletivo e valorização de atitudes e comportamentos sociais. Assim sendo, diferentemente da ótica individualista, que supõe o sucesso de cada um, isoladamente, o trabalho ancorado na perspectiva de projetos privilegia a evolução de todo grupo, incluindo aí professores e estudantes, sem 
desconsiderar a aprendizagem experiencial (SILVA, RIOS, 2018) que cada um dos participantes produz, ao inserir-se nas problemáticas reais e cotidianas que atravessam o ensino na escola. No caso do estudo em tela, considera-se às problemáticas inerentes ao ensino e estudo do espaço geográfico, com foco nas vivências e experiências que nesse campo de estudo se produzem ao se problematizar questões cotidianas e locais. Na dinâmica da Pedagogia de projetos, os processos de ensino e de aprendizagem articulam-se com vistas a produzir objetivos pedagógicos, com vistas a que professores e estudantes logrem aprendizagens significativas.

Hernández e Ventura (1998, p. 63), considerando a dinâmica da organização de projetos no campo educativo, afirmam:

Definitivamente, a organização dos Projetos de trabalho se baseia, fundamentalmente numa concepção da globalização entendida como um processo muito mais interno do que externo, no qual relações entre conteúdos e áreas do conhecimento têm lugar em função das necessidades que trazem consigo o fato de resolver uma série de problemas que subjazem à aprendizagem.

Para resolver problemas de aprendizagem que emerjam das necessidades educativas dos estudantes, se faz necessário que estes estejam implicados na construção de projetos que possibilitem investigar, conhecer e problematizar as temáticas que os atravessam ou que os mobilizam a querer a aprender. Assim sendo, e segundo o que preconiza Moura (2010) o trabalho pedagógico envolvendo com projetos constitui uma das posturas metodológicas de ensino mais dinâmica e eficiente, sobretudo pela sua força motivadora e aprendizagens em situação real, de atividade globalizada e trabalho em cooperação.

Segundo Ventura (2002), a pedagogia de projetos é caracterizada a partir da síntese de quatro conceitos: representação, identidade, negociação e rede. No campo da pedagogia de projetos, representação concerne ao caráter interpretativo que cada indivíduo ou grupo atribui aos diferentes aspectos da realidade, dado 
que, em uma sociedade da informação como a que vivemos, todos têm algum conhecimento, uma representação, sobre todas as coisas.

Segundo Santos (1996), no meio-técnico-científicoinformacional os indivíduos têm, potencialmente, uma maior possibilidade de acesso às informações devido à revolução técnicocientífico e informacional, o que facilitou o acesso às TIC. Nesse contexto, em que o acesso à informação está garantido, é necessário que o professor utilize estratégias que, de fato, induzam os alunos a explorar essas informações de maneira mais criteriosa e reflexiva, pois, ao se fazer isso, a aprendizagem produz significados.

O segundo conceito, identidade, refere-se às impressões que marcam na personalidade de cada sujeito após a realização de atividades sociais, cuja aprendizagem é uma dimensão fundante na construção das identidades. A pedagogia de projetos contribui na construção de identidades intelectuais, uma vez que os alunos estarão reunidos em grupo para realizar uma atividade. Cada qual buscará reconhecimento (de forma que afete positivamente a sua identidade) através do que expressam da sua identidade associada aos conhecimentos, competências, imagens de si mesmo.

O terceiro, a negociação, tange às propostas que cada membro de um projeto possui e que coletivamente necessita decidir quais caminhos deve-se tomar e porquê, conformando a noção de que o conhecimento é sempre uma obra coletiva. A negociação acompanha todo o projeto, mas vale ressaltar que uma das etapas da pedagogia de projetos que mais se manifesta, a negociação, é a escolha do tema a ser desenvolvido no projeto, uma vez que o tema deve ser de interesse dos alunos através de um consenso com o professor, de maneira que contemple as intenções pedagógicas da escola para uma determinada série.

O quarto, rede, tem a ver com a produção do olhar do aluno para com a escola como um local de produção de conhecimento que não se encerra em si mesma, mas se articula com os demais pontos (externos à escola) que podem (devem) participar da construção das aprendizagens. Por exemplo, os alunos podem produzir conhecimento através de uma pesquisa na biblioteca, na internet, dentre outros espaços (seja ele, espaço ou ciberespaço), ou seja, é possível articular diferentes espaços em rede para realizar as 
atividades do projeto. As possibilidades presentes na composição dos espaços hoje permitem que, através da apropriação diferenciada dos objetos, se produzam ações diferenciadas. Como nos mostra Milton Santos (1996, p. 17),

Nunca o espaço do homem foi tão importante para o destino da História. Se, como diz Sartre, "compreender é mudar", fazer um passo adiante e "ir além de mim mesmo", uma geografia refundada, inspirada nas realidades do presente, pode ser um instrumento eficaz, teórico e prático, para a re-fundação do Planeta.

É a partir destes quatro conceitos apresentados que,

Chamamos de "projeto" a uma ação negociada entre os membros de uma equipe, e entre a equipe e a rede de construção de conhecimento da qual ela faz parte, ação esta que se concretiza na realização de uma obra ou na fabricação de um produto inovador. Ao mesmo tempo em que esta ação transforma o meio, ela transforma também as representações e as identidades dos membros da rede produzindo neles novas competências, através da resolução dos problemas encontrados. (VENTURA, 2002, p. 4)

É nessa perspectiva que a pedagogia de projetos se apresenta como uma possibilidade de aprendizagem significativa por parte dos estudantes em situação escolar. Incentivados a construir soluções para os problemas propostos os estudantes percebem a necessidade de consultar os conteúdos pré-existentes sobre aspectos dos problemas, analisar ideias, adequar conteúdos, sistematizar informações, etc. de tal forma que eles venham a compreender o conhecimento como um processo de construção, do qual eles próprios são sujeitos. Sem falar no fato de que essa pedagogia possibilita o desenvolvimento de questões interdisciplinares, uma vez que é necessário que os estudantes recorram a diferentes áreas e conhecimentos para produzir entendimentos sobre um dado fenômeno ou situação investigada. 
O que pretendemos salientar é que durante a produção de um projeto, é necessário que os estudantes - por intermédio do professor - se sintam incentivados a investigar, que dialoguem sobre as propostas, negociem e decidam quais caminhos percorrer e qual conhecimento utilizar e porquê utilizá-lo. Ao fazer isso, os estudantes, que devem ser os protagonistas do projeto, corroboram para que o conteúdo apreendido na formação escolar produza sentidos, sobretudo pela relação com a interdisciplinaridade que se faz necessária e fundante para que o conhecimento seja tecido em uma rede de diferentes áreas e saberes.

Além de contribuir para que o aluno produza sentidos acerca de um determinado conteúdo, a pedagogia de projetos também pode ser um meio para tornar as estratégias de produção de conhecimento como objetos de ensino, a exemplo da leitura, pesquisa, escrita, capacidade analítica e comparativa, representação espacial, dentre outras, tudo depende dos objetivos adotados pelo professor para motivar e orientar os alunos na produção do projeto.

É de suma importância que o professor na contemporaneidade trabalhe com o fomento de virtudes intelectuais combinado com estratégias de produção de conhecimento, uma vez que mais vale o aluno aprender a estudar e ter uma boa leitura e escrita, do que apenas apreender o conteúdo de uma disciplina, pois ao desenvolver as suas virtudes intelectuais, ele se torna cada vez mais autônomo e criterioso para filtrar as informações que o mundo tem a oferecer durante o processo de produção do seu conhecimento. Tal concepção é tecida numa representação que Leite (1996) desenvolveu, denominando-a de concepção integradora de aprendizagem, conforme representação a seguir:

Figura 1- Concepção Integradora de Aprendizagem

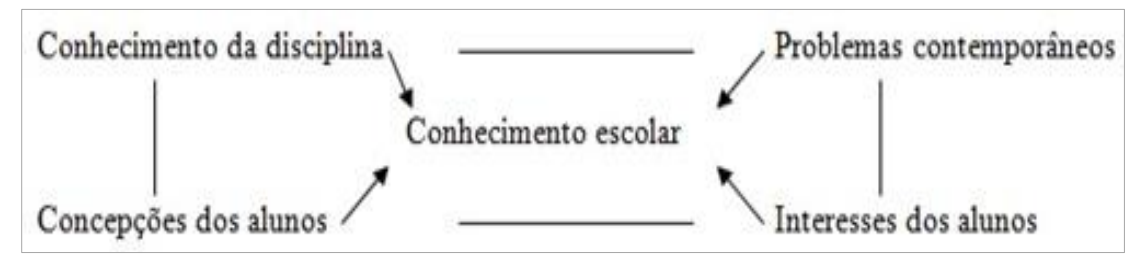

Fonte:Leite (1996, p.4) 
Os projetos podem ser elaborados por um tema/problema contemporâneo, isso não quer dizer que o professor deixará de cumprir o papel de mediador que faz com que ele compareça de forma ativa ao processo do conhecimento da ciência a qual ele foi formado para lecionar.

A elaboração de projetos, como afirma Leite (1996), consiste numa concepção integradora, pois além de envolver um problema contemporâneo e o conhecimento da disciplina, é possível que a concepção dos alunos seja posta em pauta, no tocante às negociações que acontecem durante a produção do projeto.

É importante perceber a diferença de uma educação centrada nos conteúdos conceituais e na reprodução para uma educação centrada na aprendizagem em que os conteúdos das diversas disciplinas são ferramentas de compreensão e interpretação da realidade, demarcando o lugar da interdisciplinaridade nessa construção, que se dá pela possibilidade do estudante produzir conhecimentos a partir de diálogos entre diferentes áreas do conhecimento. Nisso incide, também a concepção de uma formação laica, produzida a partir da curiosidade e da inventividade dos estudantes. O que está em jogo em uma proposta e outra é a concepção de formação.

Vale salientar que o professor precisa motivar os alunos, fomentar o interesse dos discentes pelo mundo a partir da elaboração de bons problemas e estratégias interessantes e acessíveis de abordagem do problema, pois se não há uma atitude favorável dos alunos, pode comprometer a intenção do projeto.

Destacamos algumas intencionalidades que o professor deve ter para instigar os alunos a construir o projeto: torná-los conscientes do projeto e fazê-los com que selecionem informações necessárias à resolução do problema; fazer com que os alunos saibam como obter informações e interagir com elas; constituir nos alunos um pensamento democrático (muito importante para a tomada de decisões coletivas); fundar nas reflexões deles a necessidade de negociar a razão segundo critérios científicos.

Para tanto, o professor ao realizar um projeto deve fazê-lo no intuito de que, conforme Zabala e Arnau (2010 p. 11) "O importante da escola é formar pessoas e não aplicar projetos, a filosofia dos 
projetos é mais importante que o projeto propriamente dito". Dessa forma, o principal objetivo da pedagogia de projetos não é o produto em si, mas fazer com o que os alunos aprendam a aprender.

Partindo da concepção apresentada neste tópico, no qual compreendemos que mais vale as aprendizagens que os alunos desenvolvem no espaço escolar do que decorar o conhecimento de um saber científico (particularmente associado ao método mnemônico), propomos no próximo tópico uma discussão sobre duas abordagens da geografia escolar e justificamos qual delas é mais adequada para a construção do conhecimento na atualidade.

\section{O ENSINO DE GEOGRAFIA E A EDUCAÇÃO GEOGRÁFICA}

Segundo Giovana Zen ${ }^{3}$, desde meados do século XIX, a relação didática se caracterizou, primordialmente, pela alocação de alunos organizados por idades em sala de aulas com a adoção de um quadro negro que "normalizou" o ensino, definiu um contrato didático dos modos de aprender e de ensinar, que pode ser traduzida por todos os alunos aprendendo e todos os professores ensinando as mesmas coisas, em todos os lugares - o que uniformizou do espaço escolar e do ensino.

Neste modelo, é possível verificar a primazia do ensino em relação a aprendizagem. Os conteúdos conceituais das diversas disciplinas figuram como algo a ser transmitido aos estudantes, que devem ser capazes de apreendê-los da forma mais próxima ao que foram enunciados e reproduzi-los.

Callai (2011) afirma que a educação geográfica está além de ensinar a Geografia a partir da transmissão de conteúdo. Educar geograficamente requer que o professor estimule o aluno a produzir um olhar e pensar geográficos mais apurados dos fenômenos sociais e naturais espacializados.

A professora Carolina Busch Pereira, em vídeo promocional da BNCC $^{4}$ afirma que a Geografia a partir do ideal de educação

\footnotetext{
${ }^{3}$ Apontamentos de aula sobre tecnologia e educação. Documento em PPT.

${ }^{4}$ Vídeo disponível emhttps://www.youtube.com/watch?v=84Pc1Vk-750\&t=25s. Acesso em 20 de agosto de 2019.
} 
geográfica "é uma disciplina capaz de atribuir sentido à relação das pessoas e dos produtos sociais com a natureza". Ela também afirma que segundo os autores da BNCC, para que os alunos compreendam - mundo a partir das bases da Geografia "eles precisam ser estimulados a pensar espacialmente e a desenvolver o raciocínio geográfico". Para isso é necessário que a educação geográfica se faça a partir de alguns princípios do raciocínio geográfico, tais como: a analogia, a conexão, diferenciação, distribuição, extensão, localização e ordem.

O professor de Geografia que decide educar geograficamente os seus alunos, do que meramente ensinar um conteúdo da Geografia, atua como agente que irá auxiliar o aluno a compreender melhor a realidade através do conhecimento sistematizado pela Geografia, atuando no desenvolvimento de competências e de ferramentas teóricas que permitam a produção de significação e interpretação do mundo, ou seja, esta ciência deve ser apresentada como uma das possibilidades de análise do mundo.

\begin{abstract}
Novas territorialidades emergem diante da complexidade em que se apresenta o mundo e, a Geografia se constitui numa ferramenta para entender este mundo. Neste sentido, para oportunizar que as pessoas compreendam a espacialidade em que vivem através da educação geográfica, se busca construir uma forma geográfica de pensar, que seja mais ampla, mais complexa, e que contribua para a formação dos sujeitos, para que estes realizem aprendizagens significativas e para que a geografia seja mais do que ilustração (CALLAI, 2011 p. 129).
\end{abstract}

Compreende-se por aprendizagem significativa, uma interação entre o conhecimento do que o sujeito mediado já sabe entre o que o mediador objetiva ensinar, ou seja, trata-se de uma aprendizagem que não segue apenas a vontade de quem media (não-arbitrária), pois utiliza-se de "algum conhecimento especificamente relevante já existente na estrutura cognitiva do sujeito que aprende" (MOREIRA, 2010). 
A educação geográfica se caracteriza então, pela intenção de tornar significativos os conteúdos para a compreensão da espacialidade $e$, isso pode acontecer através da análise geográfica, que exige o desenvolvimento de raciocínios espaciais. Este é o caminho estabelecido para analisar, entender e buscar as explicações para o que acontece no mundo, para os problemas que a sociedade apresenta (CALLAI, 2011 p. 131).

Pode-se compreender então que 0 ato de educar geograficamente um aluno é oferecer a ele uma maneira de enxergar o mundo sob as lentes da Geografia. Para chegar a esse "feito" o professor pode tornar a aprendizagem significativa, apresentando as possibilidades que a Geografia tem para analisar a sociedade e a natureza, e de que forma esse conhecimento é pertinente para a formação do indivíduo e da sociedade.

Uma das formas de se gerar uma aprendizagem significativa na educação geográfica é desenvolvê-la sob o prisma da pedagogia de projetos, em que, segundo Moura (2010) os discentes motivam-se para a construção do trabalho pedagógico ancorado na pedagogia de projetos, sobretudo pelos aspectos motivadores e de aprendizagens em situação real, de atividade globalizada e trabalho em cooperação, o que são elementos basilares para a produção de uma aprendizagem significativa, para a qual o estudante atribui sentido. Nas questões da educação geográfica isso se visibiliza pela dimensão de um trabalho com as realidades vivenciadas, principalmente em se tratando de evidenciar o cotidiano da educação geográfica, na qual o estudante, naturalmente, está imerso, pois vive no espaço geográfico.

Pensar a concepção de uma aprendizagem significativa encontra raízes na ideia fundamental da psicologia cognitiva de Ausubel (1980), a partir da qual o referido autor concebe que a aprendizagem se dá por meio da assimilação de novos conceitos e proposições dentro de conceitos preexistentes e sistemas proposicionais já possuídos pelo aprendiz desde que se atendam as seguintes condições: 1) O material a ser aprendido deve ser conceitualmente claro e apresentado com linguagem e exemplos relacionáveis com o conhecimento anterior do aprendiz; 2) 0 
aprendiz deve possuir conhecimento anterior relevante e; 3) 0 aprendiz precisa ter vontade de aprender de modo significativo (NOVAK; CAÑAS, 2010, p. 11).

Para Fink (2003) a aprendizagem significativa é aquela em que o ensino resulta em algo verdadeiramente significativo em termos da vida dos alunos. Na aprendizagem haverá um desejo do estudante por alcançar resultados importantes que levem a mudanças de alguma coisa importante, sobretudo no campo da Educação geográfica, condição basilar para que o próprio estudante perceba a relevância das aprendizagens significativas de conhecimentos para a vida, logradas durante e após o processo de ensino. Isso requer que durante o processo os estudantes assumam uma postura de engajamento, tornando-se envolvidos na sua aprendizagem. Com isso, os resultados visibilizam-se por mudanças significativas nos estudantes. Tal condição resulta, também, no processo de ensino, por desenvolvimento de estratégias que os professores utilizam a fim de promoverem o desenvolvimento de aprendizagens. A esse respeito, a pedagogia de projetos se constitui como uma estratégia que favorece ao desenvolvimento de uma aprendizagem que se estrutura nos paradigmas apresentados por Ausubel (1980)

\section{A PEDAGOGIA DE PROJETOS NA EDUCAÇÃo GEOGRÁFICA E O USO DAS TIRINHAS NO TEMA DO SEMIÁRIDO}

Se no lugar do "ensino da geografia" optamos por uma perspectiva de educação geográfica, devemos reconhecer que o método transmissivo não é o mais adequado e, em seu lugar, devemos optar por uma estratégia de resolução de problemas, que favorece o trabalho dos professores Geografia que veem na educação uma forma de produção de sentidos para o mundo ou, em outras palavras, que promova uma aprendizagem significativa.

A partir de problemas geográficos, os alunos podem desenvolver projetos, e durante o processo de produção eles irão desenvolvendo ferramentas pertinentes para resolver o problema. A resolução sobre o problema poderá ser desenvolvida sobre forma de um produto. 
As tirinhas são uma forma de expressão que pode ser utilizada como linguagem e mediação da produção de conhecimento na pedagogia de projetos, pois elas são um ótimo material didático para se fazer um exercício de síntese sobre o conhecimento produzido pelos alunos ao longo do projeto, pois através das falas inseridas nos balões de conversação ou na parte gráfica das tirinhas, pode-se inserir um conhecimento que fora apreendido durante o projeto.

Tomando o semiárido como ponto de partida, propusemos discutir o problema do êxodo rural que consiste na migração de habitantes oriundos da zona rural para a zona urbana. Este processo quando associado ao semiárido muitas vezes está relacionado à seca, como se não fosse possível conviver sob as condições climáticas do sertão, negando de certa forma o caráter social que está por detrás do êxodo rural (a ausência de políticas públicas para acesso à água, assim como do uso e ocupação do solo no sertão, além da falta de financiamentos para pequenos produtores rurais, por exemplo).

Em decorrência das reflexões em torno desse problema, é pertinente discutir vários problemas relacionados à seca. Dentre os quais, é possível, uma pedagogia de projetos, pensar sobre estratégias populares de convivência com a seca. Um ótimo exemplo são as cooperativas de economia solidária no semiárido, que atuam com a ideia de conviver com a seca.

Para tanto, é de suma importância que se faça inicialmente um trabalho de investigação das características físicas desse ambiente (relevo, clima, vegetação e hidrografia) para então buscarmos algumas formas de produção espacial tradicionais e contemporâneas que nos ajudem a pensar a possibilidade de se conviver com o semiárido.

\section{TIRINHAS: um gênero textual importante na educação geográfica}

A prática educativa está muito além da formação do professor de geografia. E é sob essa premissa que se encontra uma proposta que desafia a tradição transmissiva, abrindo as possibilidades de trabalho que não são tão seguras, mas possuem a possibilidade de 
transformar o espaço escolar de tal forma que se transforme em um espaço de liberdade de conhecimento e rigor intelectual.

O saber fazer deve estar sempre a despertar o interesse do professor na competência, integração do conhecimento do aluno, no reconhecimento de quanto é complexa a educação, transformandoo em um professor crítico e reflexivo. E é nesse sentido que se torna fato dizer que o espaço escolar se transformou em um espaço pouco significativo para todos: professores e estudantes.

Um espaço por si só, não atraí o aluno, nem empolga o professor a se dedicar construir dinâmicas e aulas que prendam a atenção dos estudantes. À proporção que algo é construído dentro desse espaço, as percepções, o convívio, a troca de informações, faz com que esse lugar passe a ser parte integrante do indivíduo e responsável pelas suas aprendizagens. Visto que, quando se fala em aprendizagens, não se delimita somente a escola, mas todas as aprendizagens proporcionadas a partir das relações coletivas.

A escola, como instituição social, deve proporcionar uma melhoria nas relações interpessoais, devendo facultar o conhecimento, destinando-se a realidade do discente. A ideia de trabalhar com o material didático deve estar de acordo com projeto pedagógico da disciplina, sendo assim, o professor deverá adequar ao público alvo, fazendo a melhor escolha para a produção do conteúdo. Neste contexto, deve conceder ao discente a aquisição de uma consciência crítica que lhe amplie a visão de mundo.

O gênero textual tirinhas, segundo Marcuschi (2008), são histórias em quadrinhos, que em sua maioria podem apresentar textos, falas e imagens narrativas mais curtas. Elas podem ser organizadas em sequência de três a cinco quadrinhos, apresentando conteúdos de diversas formas e em algumas vezes, não apresenta a fala, mas expressam o ponto de vista do emissor. As tirinhas podem ser encontradas em livros, jornais, revistas, desse modo, convêm ser acessível a todos.

As razões que justificam o uso de tirinhas, numa articulação de trabalho educativo da educação geográfica ancorado em pedagogia de projetos, advêm da concepção de que os gêneros textuais, na concepção de Marcuschi (2008), são fenômenos históricos profundamente vinculados à vida cultural e social, surgindo 
de acordo com as necessidades e atividades socioculturais. Nessa lógica, a educação geográfica se insere no campo da compreensão sociocultural que possibilita o estudante problematizar e estudar fenômenos espaciais e geográficos. No entendimento de Marcuschi (2008), bem como no de Rojo (2000), os gêneros textuais caracterizam-se muito mais por suas funções comunicativas, cognitivas e institucionais do que por suas peculiaridades linguísticas e estruturais. Por isso, ressalta que não existem gêneros textuais ideais para tratamento em sala de aula, mas que é possível eleger gêneros para o ensino de qualquer área, desde que se considere as especificidades do gênero e os objetivos de ensino.

Em educação geográfica, o uso de tirinhas possibilita aos estudantes compreenderem, contextualizarem, além de mobilizarem apreciações culturais próprias da educação geográfica, a partir do contexto evidenciado. Trabalhar com as tirinhas pode se tornar um objeto moderno, que dinamiza com a realidade de todos os públicos, tornando-os mais críticos. Vale salientar que não é papel apenas do professor de português ensinar os alunos a lerem melhor, mas todo professor tem essa responsabilidade.

Durante um longo tempo, as tirinhas foram motivo de rejeições e críticas, presumiam que a facilidade a qual os textos promoviam, causasse o afastamento dos alunos da leitura. Após anos, foram lentamente incluídas nos livros didáticos, vindo a ser utilizadas atualmente em múltiplas áreas do ensino, potencializando as discussões e concepções sobre a interdisciplinaridade. Tornaram-se, assim, a base para a produção da interdisciplinaridade, pois as tirinhas tanto abordam diferentes assuntos, como servem para a produção de diferentes temáticas. É um gênero textual que congrega a possibilidade de transitar e produzir sentidos em diferentes áreas do conhecimento.

As tirinhas, como material didático podem ser utilizadas como instrumento de comunicação e interpretação, ou seja, enquanto linguagem. $O$ material de apoio às aulas deve proporcionar clareamentos teóricos, facilitando o diálogo entre professor/aluno, podendo também atribuir uma melhoria de sua qualidade proporcionando aos estudantes auxílio no processo de aprendizagem. 
Vale salientar que o trabalho a partir dos gêneros textuais, pode facilitar o desenvolvimento da leitura e da escrita, fazendo com que os alunos possam adquirir uma melhor compreensão sobre o assunto abordado ou trabalhado pelo professor. Ademais, as tirinhas ganharam uma potência comunicativa com o advento da tecnologia, em que as possibilidades de relação entre imagem e texto ganharam maior condição de exploração temática, ampliada pela condição tecnológica de sua produção.

As tecnologias da informação são cada vez mais presentes na vida dos alunos, pois viabiliza de forma eficiente a organização dos negócios, do poder e da cultura. A partir daí a inserção das novas tecnologias na escola deve promover o desenvolvimento cultural do aluno.

Para Moran (2000), existem múltiplas possibilidades de utilização das tecnologias de informação e comunicação na realização de atividades escolares. Para tanto, é de bom tom que o professor trabalhe numa visão inspirada no construtivismo, ou seja, na crença de que o aluno construirá o seu próprio conhecimento a partir de sua interação com o mundo e com a mediação do professor.

No mundo contemporâneo, a presença dos computadores tem mediado boa parte da relação que os sujeitos mantêm com o conhecimento e, na escola, ele pode vir a ser um aliado para a aprendizagem na medida em que possibilita a interação de múltiplas referências como livros interativos, utilização de softwares educativos, museus, mídias, etc. São, portanto, ferramentas poderosas para motivar e possibilitar que os estudantes explorem sua criatividade e inventividade, tanto na produção de tirinhas em que as temáticas geográficas se presentificam, como na interpretação, em que as imagens são fundantes para a compreensão do espaço geográfico.

Enfim, as tirinhas congregam diferentes aspectos estruturantes que permitem a compreensão de como os estudantes podem realizar interpretações a partir de conhecimentos interdisciplinares, para os quais a intersecção se produz, no caso da tirinha, pela relação da imagem e texto, possibilitando a produção de diferentes modos de entender e interpretar os fenômenos e os espaços geográficos. As tirinhas, constituem-se relevantes estratégias pedagógicas que podem integrar fases e etapas de uma pedagogia 
de projetos em nome da produção autônoma de conhecimento que os estudantes podem fazer, sendo protagonistas dos seus processos de aprender, gerando, assim, aprendizagens significativas.

\section{CONSIDERAÇÕES FINAIS}

O desenvolvimento do presente artigo permitiu a compreensão da pedagogia de projetos como possibilidade de se promover uma educação geográfica, mediada pela linguagem das tirinhas.

A incorporação do discente no contexto da aula valoriza a construção do conhecimento, pois quando se tira a sua autonomia de gerar e construir seu próprio conhecimento, podemos dizer que estamos retirando seu direito em aprender. Torna-se considerável construir atividades que instiguem os alunos, movendo emoções de toda turma. E como foi discutido ao longo do trabalho, a pedagogia de projetos é uma proposta metodológica que dá autonomia ao aluno para que ele produza o seu conhecimento.

Para realizar a educação geográfica verificamos na pedagogia de projetos uma ótima possibilidade, já enquanto um produto dessa interação identificamos a importância das tirinhas como uma linguagem que pode ser utilizada para expressar o que fora produzido ao longo do projeto. Neste contexto, as tirinhas constituem interessante mecanismo, por meio do qual os estudantes exploram sentidos, criam significados e dinamizam a aprendizagem que desenvolvem em torno do conhecimento geográfico. Assim, é possível entender que a interdisciplinaridade emerge como elemento fundante para que os estudantes possam compreender e desenvolver o pensamento em torno de questões geográficas utilizando-se do gênero textual como ferramenta para potencializar a aprendizagem escolar.

Trabalhar com a perspectiva de educação geográfica é um passo importante para que o professor de geografia passe a perceber a importância não só do ensino, mas também da aprendizagem, sobretudo tecida pelas questões da interdisciplinaridade, por meio da qual os estudantes podem transitar em diferentes linguagens a fim 
de compreender e produzir sentidos para o que estudam, refletem e aprendem.

\section{REFERÊNCIAS}

AUSUBEL, D. P.; NOVAK, J. D.; HANESIAN, H. Psicologia educacional. Tradução Eva Nick. Rio de Janeiro: Interamericana, 1980.

CALLAI, C. H. A Geografia escolar e os conteúdos da Geografia.

Revista Anekumene. n. 1, p. 128 - 139, 2011.

FINK, L. D. Creanting significant learning experiences: an integrated approach to designing college courses. Jossey-Bass: San Francisco, 2003

FREIRE, P, Pedagogia do Oprimido, Rio de janeiro: Paz e Terra, 2014.

HERNÁNDEZ, F.; VENTURA, M. A organização do currículo por projetos de trabalho: o conhecimento é um caleidoscópio. 5. ed. Porto Alegre: Artmed, 1998.

LEITE, L. H. A. Pedagogia de projetos: intervenção no presente.

Presença Pedagógica, v. 2, n.8, 1996

LÜDKE, M. O Trabalho com Projetos e a Avaliação na Educação Básica. In: HOFFMANN, J (org). Práticas avaliativas e aprendizagens significativas. Porto Alegre: Mediação, 2003.

MARCUSCHI, L.A. Produção textual, análise de gêneros e compreensão. São Paulo: Parábola, 2008.

MORAN, J. M. et al. Novas tecnologias e mediação pedagógica.

São Paulo: Papirus, 2000.

MOREIRA, M. A. O que é afinal aprendizagem significativa? UFRGS: Cuiabá, 2010. Disponível em:

http://moreira.if.ufrgs.br/oqueeafinal.pdf. Acesso em 25 de Julho de 2017. 
MOURA, D. P. Pedagogia de Projetos: Contribuições para Uma Educação Transformadora, 2010.

http://www.pedagogia.com.br/artigos/pedegogiadeprojetos/index.p hp?pagina=0. Acessado em 02 de março de 2021.

NOVAK, J. D.; CAÑAS, A. J. A teoria subjacente aos mapas conceituais e como elaborá-los e usá-los. Práxis Educativa, Ponta Grossa, v.5, n.1, p. 9-29, jan.-jun. 2010. Disponível em http://www.periodicos.uepg.br/ Acessado em 28 se nov. de 2019.

ROJO, R. (Org.) A prática de linguagem em sala de aula: praticando os PCNs. São. Paulo: EDUC; Campinas: Mercado de Letras, 2000.

SANTOS, M. A aceleração contemporânea: tempo mundo espaço mundo. In. SANTOS, M. Técnica Espaço Tempo: Globalização e meio-técnico-científico-informacional. São Paulo. Ed HUCITEC, 1996.

SILVA, F. O. da.; RIOS, J. A. V. P. Aprendizagem experiencial da iniciação à docência no PIBID. Práxis Educativa, Ponta Grossa, v. 13, n. 1, p. 202-218, 2018. Disponível em:

https//doi.org/105212/praxeduc.v.13i1.0012. Acesso em: 10 fev.2019

VENTURA, P. C. S. Por uma pedagogia de projetos: uma síntese introdutória. Educ. tecnol., Belo Horizonte, v.7, n. 1, p. 36 - 41, 2002.

ZABALA, Antoni. \& ARNAU, Laia - Como aprender e ensinar competências. Porto Alegre. Ed Artmed, 2010.

Submetido em: Abril/ 2020.

Aceito em: Janeiro/ 2021. 